\title{
Pupillary changes and reaction time with varied stimulus uncertainty
}

\section{JOHN L. BRADSHAW, Monash University, Clayton, Victoria, Australia}

In a reaction-time task, an increase in stimulus uncertainty led to increased $R T$. This was achieved by varying the number of possible sensory modalities for the signal, changing the length or variability of a warning foreperiod, and concurrently presenting masking noise. At the highest levels of uncertainty, concurrently-monitored pupillary dilation showed an overall flattening of associated response peaks, together with a rise in baseline levels. There was also evidence of expectancy phenomena with nonoccurring, anticipated signals.

Elliott (1964) has reviewed the effects of long and short warning-foreperiods upon both reaction-times (RT) and EEG changes. Fernandez-Guardiola et al (1968) noted also the effects of expectancy phenomena and habituation at both the motor and electrical levels with similarly varied foreperiods. Divided set, where the signal-to-respond may appear in more than one sensory modality, may further increase stimulus uncertainty and RT (Mowrer et al, 1940; Malmo, 1966).

The purpose of this experiment was to ascertain whether such RT increases associated with $S$ uncertainty would affect baseline and response peak phenomena in concurrently recorded pupillary diameters.

\section{APPARATUS}

The photographic and optical equipment used for recording and measuring pupillary diameter has been described already (Bradshaw, 1968). An auditory warning-signal could be presented over earphones. If present, it was followed by either a long or short warning foreperiod of $5 \frac{1}{2}$ or $2 \frac{3}{4} \mathrm{sec}$, respectively. The response-signal could be preset either to an auditory tone of slightly different frequency, or a visual signal. With the latter an extremely small bulb situated in the middle and to the back of a brightly illuminated back projection screen cast a faint glow where otherwise its shadow had been. It was of the same duration $(1 / 3 \mathrm{sec})$ and onset characteristics as the sound signal, and was no brighter than the illuminated background, as measured by an SEI spot photometer, and was just detectable as a signal. It was afterwards confirmed that its illumination was below the level necessary to cause a photic response, in a comparison with the effects of the auditory signal.

The Ss' RT was measured to the nearest hundredth of a second from onset of response-signal. A marker was put on the recording film whenever any kind of signal or response occurred.

\section{PROCEDURE}

There were three experimental conditions. In the first, there was no warning-signal. The response-signals were randomly either auditory or visual. A constant level of white noise was continuously presented over the earphones, so that the auditory response-signal was just detectable. In this way the two types of signal were of approximately equal difficulty in detection.

In the second and third conditions, the warning-signal was always present, and both it and the response-signal were always auditory. The warning-foreperiod was randomly of either long or short duration in the second condition, while in the third it was always short. The level of masking white noise was reduced in these two conditions.
A counterbalanced order of presentation was employed and considerable prior practice in all conditions was given, up to performance asymptote. Each condition was represented twice, each time with eight sequences of signal and response. Each sequence was of $15 \mathrm{sec}$ duration with the exception that in the first condition, with absence of warning-signal, the response-signals were randomly spaced, being between 11 and 19 sec apart.

All Ss (four male, four female) were aged between 20 and 30 , and were familiar with the procedure. They were students or staff.

\section{RESULTS}

The averaged RT data is presented in Table 1. The effect of increasing stimulus uncertainty is apparent. Taking the eight Ss individually, the averages of the no-warning condition were consistently greater than the corresponding ones in the variable foreperiod group $(p=.005$, one-tailed Wilcoxon matched-pairs signed-ranks). Similarly, the variable condition resulted in greater reaction-times than the constant-foreperiod condition, with only one exception $(p<.01)$. The RT obtained to the long foreperiods proved lower than those to the short foreperiods in the variable condition $(p=.005)$. No consistent differences, however, were noted between the auditory and visual RT in the no-warning condition. These proved large and extremely variable. The average $R T$ of the long foreperiod group within the variable condition more closely approximated the values attained by the constant-short than did the variable-short.

A continuous pupillary record at 2.7 intervals per sec was taken throughout. While actual measurements were taken to the nearest $.1 \mathrm{~mm}$, averages were calculated to $.05 \mathrm{~mm}$ in view of the size of N. Table 2 presents two sets of data for the various conditions. The first is the average of the highest point of the response peaks attained during response. The second gives the overall average for the last 10 records of each cycle, immediately before each new cycle of about 40 records $(15 \mathrm{sec})$.

In the no-warning condition, the response-peak proved consistently if fractionally lower than the peaks in the other three conditions $(p<.01$, Wilcoxon, two-tailed). Out of the total of 24 instances for comparison, there were two ties and five counter instances, the latter all being very small in comparative magnitude, two occurring in the one condition (variable-short), and two with a single $S$. No trends whatsoever were to be found between any pairs of the three other conditions.

The tailend comparisons showed conversely that the no-warning condition was associated with a higher overall average at the end of a cycle than the other three conditions ( $p<.01$, Wilcoxon, two-tailed). There were only three counter instances out of 24 , two again occurring in the variable-shor

Table 1

Averaged RT for eight Ss, in the Three Conditions, Taken to Nearest 5 msec

\begin{tabular}{|c|c|c|c|c|c|c|}
\hline \multicolumn{3}{|c|}{ No warning foreperiod } & \multicolumn{3}{|c|}{ Variable foreperiod } & \multirow{2}{*}{$\begin{array}{l}\text { Constant } \\
\text { Foreperiod }\end{array}$} \\
\hline uditory & Visual & Mean & Long & Short & Mean & \\
\hline 390 & 400 & 395 & 230 & 260 & 245 & 210 \\
\hline
\end{tabular}


Table 2

Pupillary Diameters in mm at the Response Peak, and for the Last 10 Records (Averaged) at the End of Each Cycle of Approximately 40 Records, or $15 \mathrm{sec}$.

\begin{tabular}{|c|c|c|c|c|c|c|c|}
\hline \multicolumn{4}{|c|}{ Peak at responding } & \multicolumn{4}{|c|}{ Tail-end averages, last 10 records } \\
\hline $\begin{array}{l}\text { No } \\
\text { Varning }\end{array}$ & $\begin{array}{l}\text { Variable } \\
\text { g Short }\end{array}$ & $\begin{array}{c}\text { Variable } \\
\text { Long }\end{array}$ & $\begin{array}{c}\text { Constant } \\
\text { Short }\end{array}$ & $\begin{array}{c}\text { No } \\
\text { Warning }\end{array}$ & $\begin{array}{l}\text { Variable } \\
\text { g Short }\end{array}$ & $\begin{array}{c}\text { Variable } \\
\text { Long }\end{array}$ & $\begin{array}{c}\text { Constant } \\
\text { Short }\end{array}$ \\
\hline 4.00 & 4.10 & 4.10 & 4.15 & 3.85 & 3.75 & 3.75 & 3.80 \\
\hline
\end{tabular}

condition, and two with a single S. Again no differences were found between any pairs of the other three conditions.

In three of the Ss, there was evidence of a small peak in pupillary dilation followed by a drop in the variable-long condition, at that point in time when a response-signal would have occurred, had that cycle instead proved to be variable-short.

\section{DISCUSSION}

Altering the levels of uncertainty relating to $S$ modality and timing was seen to affect both obtained RT and pupillary dilation. Extreme stimulus uncertainty was associated with a relatively flat pupillary curve, with lower response-peaks and raised baselines. The raised baselines could perhaps be a correlate of load (Bradshaw, 1968), while the lowered peaks could also reflect relative decrease in response readiness. The pupillary correlates of readiness or expectancy for a non-occurring signal has already been noted in some of the Ss. Fernandez-Guardiola et al, 1968, and Grey Walter et al, 1964, observed a similar phenomenon with other psychophysiological indices of expectancy.

In the variable foreperiod condition, the reduction in RT associated with long warning-foreperiods as compared with short, can probably be accounted for by a reduction in $S$ uncertainty. If a response signal has not occurred at the moment corresponding to the end of the short foreperiod, it must occur at the end of the long.

\section{REFERENCES}

BRADSHAW, J. L. Pupil size and problem solving. Quarterly Journal of Experimental Psychology, 1968, 20, 116-122.

BRADSHAW, J. L. Load and pupillary changes in continuous processing tasks. British Journal of Psychology, 1968, 59, 265-271.

ELLIOTT, R. Physiological activity and performance. Psychological Monographs: General \& A pplied, 1964, 78, 10 (Whole No. 587).

FERNANDEZ-GUARDIOLA, A., AYALA, F., \& KORNHAUSER, S. EEG, heart rate and RT in humans, variable vs fixed interval repetitive stimuli. Physiology \& Behavior, 1968, 3, 231-240.

GREY WALTER, W., COOPER, R., ALDRIDGE, V. J., McCALLUM, W., \& WINTER, A. L. Contingent negative variation an electrical sign of sensori-motor association and expectancy in the human brain. Nature, 1964, 203, 380-384.

MALMO, R. B. Cognitive factors in impairment: a neuropsychological study of divided set. Journal of Experimental Psychology, 1966, 71, 184-189.

MOWRER, O. H., RAYMAN, N. N., \& BLISS, E. L. Preparatory set (expectancy) - an experimental demonstration of its "central" locus. Journal of Experimental Psychology, 1940, 26, 357-372. NOTE

1. The author is grateful to Mrs. L. A. Frazer for her help in all the computations and measurements. 